\title{
An additional challenge of Lake Kivu in Central Africa - upward movement of the chemoclines
}

\author{
Finn HIRSLUND* \\ COWI A/S, Parallelvej 2, 2800 Kongens Lyngby, Denmark \\ *Corresponding author: fh@cowi.dk
}

\begin{abstract}
In Lake Kivu, gases accumulate, exposing the riparian population to the perils of a limnic eruption. This primary challenge has been known for years. Measurements have now established that the chemoclines in Lake Kivu are moving upward at the following total vertical flow rates (in $\mathrm{km}^{3} \mathrm{y}^{-1}$ ): $\sim 0.05$ below $390 \mathrm{~m}, \sim 0.12$ below $313 \mathrm{~m}, \sim 0.13$ below $257 \mathrm{~m}, \sim 0.25$ below $191 \mathrm{~m}$, and 1.39 below $\sim 140$ $m$ depth. The upward movement is caused by inflows to the deeper parts of the lake from water sources with different salinities and thus of different densities. As a result, they stratify at their different isopycnal levels (especially at $350 \mathrm{~m}$ and at 220 to $245 \mathrm{~m}$ depth) and mix into the waters at those levels, thus pushing up all water above, chemoclines and mixed zones alike. Water from rivers in the catchment area remains in the mixolimnion and when cold, some may sink down to the uppermost mixolimnion. Depending on the wind direction, it is suggested that alternating outflows from Kabuno Bay with variable density ends up either in the mixolimnion or at $245 \mathrm{~m}$ depth. In Lake Kivu, only the uppermost chemocline remains at the same level; in this case the upward movement results in transport of mass across the chemocline. In the uppermost mixed zone of the monimolimnion, from 130 to $180 \mathrm{~m}$ depth, the natural dilution might suffice to outbalance methane accumulation and thus to prevent any future limnic eruption from this zone. In the next mixed zone below (at 200 to $250 \mathrm{~m}$ depth), the upward displacement of dissolved gases to higher levels increases the risk of future limnic eruption. In fact, over time this risk is changed to certainty, even if gas is removed from the deeper (commercially attractive) layers. The limited dilution in this zone probably does not suffice to outbalance methane accumulation. Furthermore, if this upward movement is not prevented, probably within a decade or two a point of no return is likely to be passed, leaving us with no reliable means of responding to this challenge. It is therefore necessary to stop the upward movement by disposing $\sim 0.25 \mathrm{~km}^{3} y^{-1}$ of degassed water into the mixolimnion. It is what gas extraction plants do to the lake in the next decades that determines whether realistically a future limnic eruption from this layer may be prevented.
\end{abstract}

Key words: chemoclines, upward movement, Lake Kivu, risks, limnic eruption, double-diffusive convection.

Received:February 2011. Accepted: October 2011.

\section{INTRODUCTION}

Situated on the border between Rwanda and D.R. Congo, Lake Kivu is unique with its characteristic largescale density structure, comprising five mixed zones and four chemoclines. It is this density structure that allows magmatic $\mathrm{CO}_{2}$ as well as biogenetic $\mathrm{CH}_{4}$ and $\mathrm{CO}_{2}$ to accumulate in the lake. These biogenetic gases are accumulating and over the last decades the rate of accumulation has increased over the longer-term historical values (Schmid et al. 2004). For reasons explained in Hirslund (2012, submitted) the gases are trapped below the main chemoclines and the gas profiles largely follow the salinity profile. The risk of a limnic eruption increases as the partial pressure of the accumulating gas approaches the point of saturation. The depths immediately below the chemoclines at 257 and $313 \mathrm{~m}$ depth are closest to saturation. This poses an increasing threat to the riparian population of Lake Kivu as limnic eruptions are known to cause human fatality, as occurred previously at Lake Monoun (Sigurdsson et al. 1987) and at Lake Nyos (Freeth
1988) in Cameroon and Lake Albano in historical times (Funiciello et al. 2003; De Benedetti et al. 2008). A linear extrapolation of the results of Schmid et al. (2004) shows that without intervention, the dense gas cloud that would result from a foreseeable gas eruption from Lake Kivu (roughly a century from now) would have the potential to claim up to two million lives at today's population density. Alternatively, eruption could happen earlier with a volcanic trigger (e.g., lava inflows). The predicted limnic eruption can be averted through gas extraction (with appropriate protocols) from the lake in order to reduce the threat to acceptably low levels. This is currently underway in Lake Nyos (Kusakabe et al. 2000).

Based on existing knowledge, Kling et al. (2006) attempted to explain whether the methods or technology of gas extraction from the lake in itself could induce a major limnic eruption. Based on the insufficient information available at that time, the answer to this question was 'no'. As a result of a workshop held by the government of Rwanda in Gisenyi (Fig. 1) in March 2007, from 2007 to 


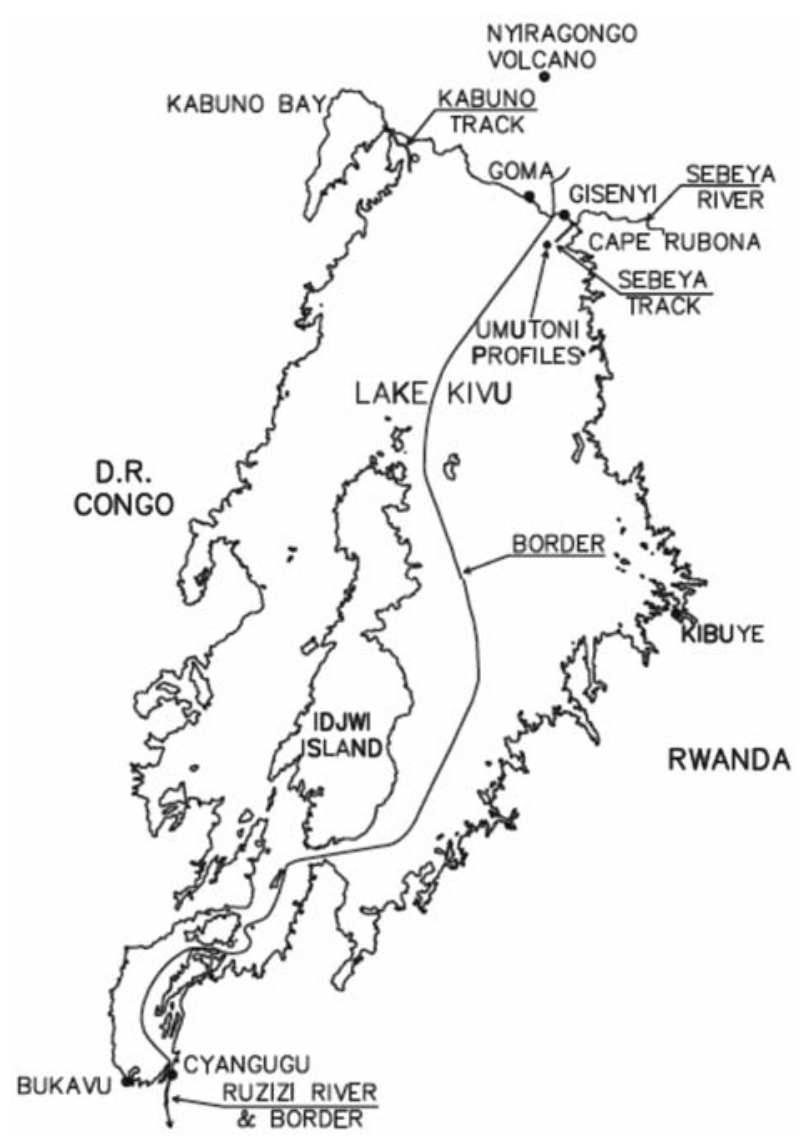

Fig. 1. Lake Kivu, located on the border between Rwanda and D.R. Congo, illustrating geographical names and locations mentioned in this article.

2009 a group of experts have worked to define rules for gas extraction with the purpose of ensuring that commercial extraction of methane may serve as the vehicle that society uses to control the gas accumulation and to reduce the existing gas deposit to acceptably low concentrations (and thus to acceptable low levels of risk) for all the foreseeable future (Boyle et al. 2009). The uncertainties related to the 1975 and the 2003/2004 gas profile measurements were discussed at length, since both parties having measured these profiles were represented in the group. In 2007 it led to the conclusion that the above forecast of a limnic eruption in the foreseeable future is trustworthy, although there is significant uncertainty as to when it would happen, possibly in the range 80 to 200 years from now. Possible reasons for this acceleration of gas accumulation over the last decades have been discussed in Pasche et al. (2010). In the course of establishing these rules it was realised that the challenge set by the ever accumulating gases in the lake requires not only removal of most of the existing gas deposit but also that it is done in a sustainable way, also leaving for the future generations the option of using commercial gas extraction as our most reliable tool for continued preservation of public safety. This continued prevention of gas eruptions is what these rules are conceived to ensure.

Among this group of experts it was also realised, that all this is only possible through the preservation of at least three of its chemoclines, the ones at $85 \mathrm{~m}, 191 \mathrm{~m}$ and 257 $\mathrm{m}$ depth. The ones at $313 \mathrm{~m}$ and at $390 \mathrm{~m}$ depth are expendable, but only under very special conditions as defined in Boyle et al. (2009) by removing initially as much gas as possible from the mixed layer in between the 257 $\mathrm{m}$ and the $313 \mathrm{~m}$ chemoclines prior to harvesting the gas from the lower strata. Deliberate modifications to the chemoclines at 85,191 , and $257 \mathrm{~m}$ depth would mean that the two governments of Rwanda and of D.R. Congo could forever loose the option of being able to control the dangers from the accumulating gases in Lake Kivu.

It was furthermore realised (Boyle et al. 2009) that if one is to maintain the ability to counteract the dangers caused by gas accumulation in the lake, for all foreseeable future, quite strict constraints must be posed on the design of gas extraction methods. The main constraints are related to 1) the level of water extraction, 2) the level of water reinjection, and 3) the density of the reinjected water. As a result, only certain issues may be left for the designers of gas extraction facilities to freely decide upon. The rules in Boyle et al. (2009) are such that, if followed, they preserve the magnitude (width) of the present $191 \mathrm{~m}$ and $257 \mathrm{~m}$ chemoclines while reducing gas pressures in the lake to acceptable levels through extracting most of the present gas deposit below $250 \mathrm{~m}$ depth. In the meantime, natural mechanisms as described below would maintain the chemocline right below the mixolimnion. For this urgent and very important purpose, the rules in Boyle et al. (2009) are indispensable. They are, however based on the assumption that the chemoclines in Lake Kivu remain at fixed depths, because this was the firm belief of some of the authors.

Degens et al. (1973) were the first to suggest that there must be at least one deep water inflow to the lake in order to cause sufficient upward movement to make up for the yearly salt losses via the outflow in the Ruzizi River. According to an assumption proposed by Schmid et al. (2005), however, the chemoclines were assumed to remain at a fixed level. This assumption has prevented the said group of experts from agreeing on the upward movement of the chemoclines, on appropriate addressing hereof, and on timely action. It is this important aspect of public safety preservation that is the main conclusion of this article in which:

1) the upward movement rates of all the lower chemoclines are quantified for the first time;

2) the consequences for future eruptions of the lake are discussed.

A proper understanding of the upward movement of 
the chemoclines is a prerequisite for safe administration of gas extraction from Lake Kivu. This is why it is considered necessary also to provide some novel technical analyses in order fully to explain the consequences of the findings in this article.

\section{DATA SOURCES}

New measurements of CTD (Conductivity, Temperature, Depth) profiles were made near Gisenyi (see location indicated on map in Fig. 1) by Umutoni et al. (2009a) on June $10^{\text {th }}, 2009$ with the objective of providing a baseline prior to the establishment of a new test facility for gas extraction from the lake. The probe used was model CTD60M from Sea and Sun Technology with the following specifications: Depth 0 to 50 bar, accuracy $\pm 0.1 \%$ fs, resolution $\pm 0.002 \%$ fs. Conductivity 0 to $60 \mathrm{mS} \mathrm{cm}^{-1}$, accuracy $\pm 0.010 \mathrm{mS} \mathrm{cm}^{-1}$, resolution $\pm 0.002 \mathrm{mS} \mathrm{cm}^{-1}$. Temperature: 2 to $+32^{\circ} \mathrm{C}$, accuracy $\pm 0.01^{\circ} \mathrm{C}$, resolution $\pm 0.001^{\circ} \mathrm{C}$. The raw data from these profiles were made available to the author and are shown in Fig. 2. The difference between the 9 profiles is not visible at the scale of the figure and the apparent 'solid' line is composed of the 18 single lines from the nine profiles, one line for the downcast and one for the upcast. Fig. 2 shows the four uppermost chemoclines that are discussed in this article.

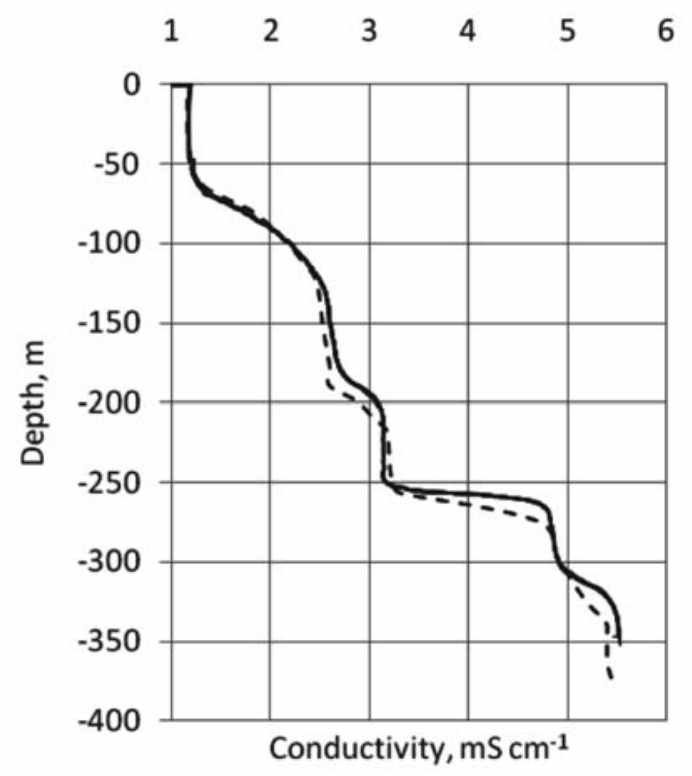

Fig. 2. Graph showing the salinity profile in Lake Kivu (data from Umutoni et al. (2009a), CTD profiles Nos. 210-218). If we name the chemoclines after the present level of their centres, it would be: $85 \mathrm{~m}$ chemocline, $191 \mathrm{~m}$ chemocline, $257 \mathrm{~m}$ chemocline and $313 \mathrm{~m}$ chemocline. The 'solid' line on the graph is in reality composed of the 18 single thin lines from these 9 profiles. The dotted line represents the calculated average of 23 profiles from 1975 as measured by Tietze (1978).

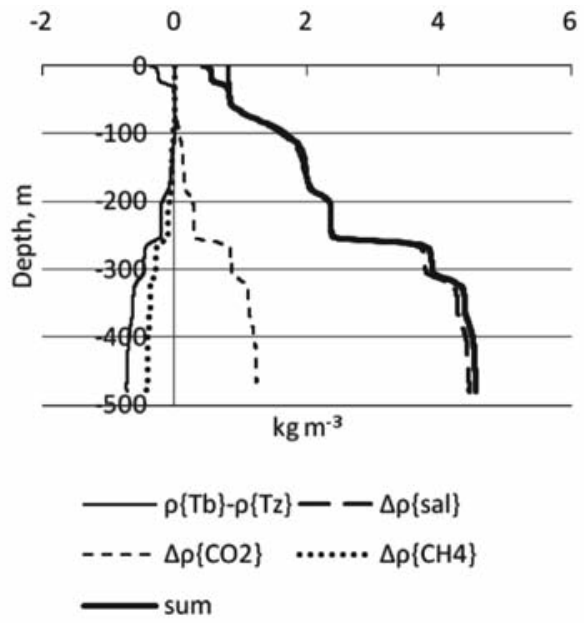

Fig. 3. Contributions from single parameters to overall density difference from top to bottom of Lake Kivu. Raw data and density calculation equation from Schmid et al. 2005. The influence of temperature is shown as the difference between the coldest point on the profile. The total calculated density profile down through the lake happens to match astonishingly well with the contribution from the salinity alone. The contributions from dissolved gases and from temperature cancel each other almost perfectly.

A stringent definition of the pycnocline would require that true density had been measured, because in doublediffusive convection it is only gravity and density differences that determine the formation, disruption and upward movements of discrete water parcels inside the single double-diffusive layers (Hirslund 2012, submitted). Among the conductivity and temperature profiles measured, the conductivity profile converted into salinity is the one that comes the closest to the density profile as shown in Fig. 3 , and it is therefore conductivity that has been used for the calculations of the chemocline, and by analogy pycnocline levels in this article.

To circumvent the natural variations, measurement errors and digitalisation errors that prevent the formulation of a perfect mathematical description of the chemoclines, the centre depth of each chemocline is defined as the level that is half-way between the two closest tangents in the mixed zones above and below the chemocline as shown in Fig. 4. This geometrical approximation to the centre level of a single chemocline is suggested to give the best accuracy.

A comparison between salinity and temperature profiles shows, that for the two chemoclines at $191 \mathrm{~m}$ and at $313 \mathrm{~m}$ depth not influenced by external disturbances (see below), this choice between use of conductivity vs temperature as an indicator of chemocline position has virtually no consequence, whereas for the disturbed chemocline at $257 \mathrm{~m}$ (see details below) the level would have been $4 \mathrm{~m}$ higher (less deep) if the temperature profile 


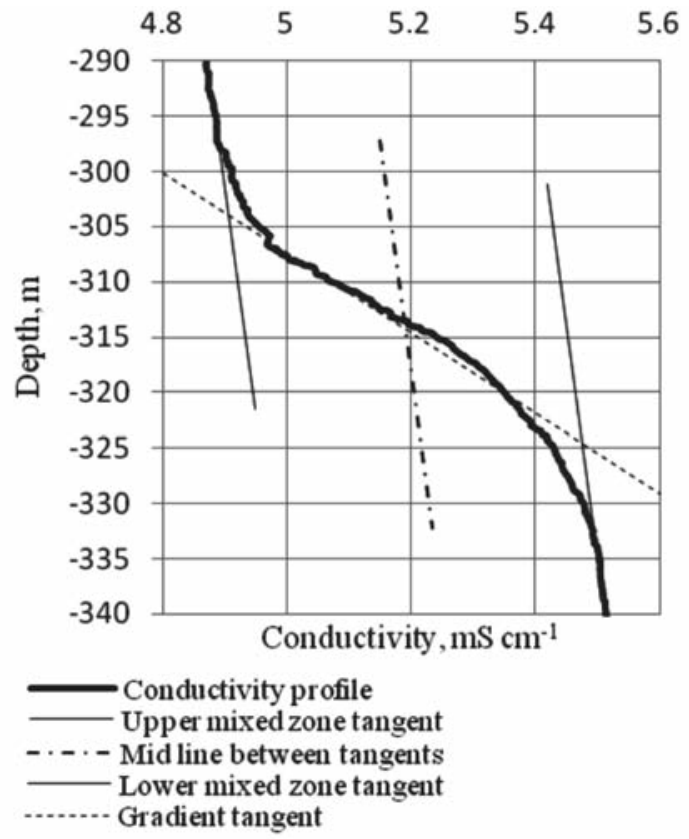

Fig. 4. Definition of chemocline parameters. The level of the centre of the chemocline is calculated as the middle between the two tangent intersection points shown (data from Umutoni et al. (2009a), CTD profile No. 210).

had been chosen. As long as the same profile is used throughout, there should be no significant error from this choice when comparing chemocline levels over time.

Between Nov. 1974 and Feb. 1975, Tietze (1978) measured 23 profiles at different locations in Lake Kivu. For depth and salinity he used instruments from NSW, Germany with the following specifications: range 20 to $30^{\circ} \mathrm{C}$, resolution: $\pm 0.001^{\circ} \mathrm{C}$ and: range 0 to $10 \mathrm{mS} \mathrm{cm}{ }^{-1}$, resolution: $\pm 0.001 \mathrm{mS} \mathrm{cm}^{-1}$. Realizing that the profiles were similar throughout the lake, Tietze (1978) then calculated the average of these 23 profiles as well as the calculated derivative of the average density profile and published this result together with one set of directly measured profiles of conductivity, temperature and in situ density. The original data were never published, and significant effort has therefore been made to read these graphs very meticulously (to the fraction of a $\mathrm{mm}$ ) from a copy blown up to around $1 \mathrm{~m}$ by $1 \mathrm{~m}$. This amount of care ensures that the reading errors (a fraction of a metre) are smaller than the errors related to transferring the calculated results to paper, the latter having been estimated to 2 metres. The chemocline centres have been determined from Tietze's 1974-75 profile in exactly the same way as defined in Fig. 4 for the 2009 profiles.

In 2004, Schmid et al. (2005) measured four more temperature and salinity profiles in an area between the Idjwi Island and Goma, and from these profiles the authors calculated average profiles, giving the density and other parameters at a $1 \mathrm{~m}$ vertical resolution. This renders the 2004 results slightly less accurate in terms of the chemocline levels. This data set is comprised of fewer profiles than the 1974-75 and 2009 data sets and is therefore less likely to capture a true lake-wide average. More emphasis is therefore placed on the new data from 2009 and the 1975 data from Tietze (1978), and these data sets are used for calculating the average movement of the single chemoclines over this period. Finally, one earlier temperature profile was reported by Degens et al. (1973). Though it is only a single profile of temperature alone, it is of interest because it is believed to be the oldest profile on record. The profile by Damas (1937) is not accurate enough in the deeper parts of the lake for such comparison.

\section{RESULTS}

The results of the chemocline position calculations are shown in Tab. 1. These calculations show a statistically significant upward migration of the three lower chemoclines from 1975 to 2009 . The linear upward movement rates in $\mathrm{m} \mathrm{y}^{-1}$ have been calculated directly from the level measurements. Based on the bathymetry of Lahmeyer and OSAE (1998), these results have then been converted into volumetric upward movement rates in $\mathrm{km}^{3} \mathrm{y}^{-1}$.

Tab. 1. Presentation of chemocline levels in three different years and calculation of the level differences and of the resulting upward movement rates.

\begin{tabular}{|c|c|c|c|}
\hline Chemocline & Upper & Main & Lower \\
\hline 1 temperature profile, early $1971(\mathrm{~m})$ & $202 \pm 5$ & $272 \pm 2$ & $325 \pm 2$ \\
\hline 23 salinity profiles in $1974 / 75(\mathrm{~m})$ & 198.9 & 263.6 & 323.0 \\
\hline 4 salinity profiles from early $2004,(\mathrm{~m})$ & 188.6 & 258.8 & 314.1 \\
\hline 9 salinity profiles on June 10th, 2009 (m) & 190.9 & 257.3 & 313.5 \\
\hline Directly calculated $\sigma$ for 2009 results (m) & 0.27 & 0.06 & 0.21 \\
\hline Estimated total $\sigma$ for the difference $(\mathrm{m})$ & 2.2 & 2.2 & 2.2 \\
\hline Upward movement, 34 year period (m) & 8.0 & 6.3 & 9.5 \\
\hline Corresponding flow rate $\left(\mathrm{km}^{3} \mathrm{y}^{-1}\right)$ & $0.25 \pm 0.07$ & $0.13 \pm 0.06$ & $0.12 \pm 0.03$ \\
\hline Corresponding flow rate $\left(\mathrm{m}^{3} \mathrm{~s}^{-1}\right)$ & 7.9 & 4.1 & 3.7 \\
\hline Water volume from 2009 depth to $130 \mathrm{~m}$ depth $\left(\mathrm{km}^{3}\right)$ & 80 & 140 & 173 \\
\hline Time for chemocline centre to reach $130 \mathrm{~m}$ depth (y) & $\sim 320$ & $\sim 1100$ & $\sim 1400$ \\
\hline
\end{tabular}




\section{Discussion of uncertainties}

The most important uncertainty in these calculations is believed to be the level of the lake surface at the time of the measurements. This level was not recorded by Tietze in 1974/75, whereas in June 2009 the level of the lake was at $1463 \mathrm{~m}$ above sea level (personal communication from L. Rwandekwe). The first hydroelectric dam over the Ruzizi River near Bukavu was established in 1958, thereby stabilizing the level of Lake Kivu. Halbwachs et al. (2002) have estimated that the level in the lake does not vary more than $\pm 0.5 \mathrm{~m}$ (between 1462 to $1463 \mathrm{~m}$ ), and this estimate of level variations has been confirmed by Pasche et al. (2010) for the period between 1945 to 2005.

For the 2009 profiles, the depth in the lake was measured (in dbar) by a pressure sensor. By multiplying with the local gravity constant and with the calculated average of the overlying water column density, the dbar reading was converted into metres depth just as did Tietze with his 1975 measurements (pers. comm.). Furthermore, with the 2009 profiles the zero point error was recorded before and after each series and resulted in small corrections to the measured values, typically on the order of $0.1 \mathrm{~m}$. Taking into consideration both drift and repeatability of the instrument, the uncertainty on the single determinations of the momentary distance from the lake surface to the centre of the chemoclines would be around $\pm 0.2 \mathrm{~m}$.

In order to calculate one standard deviation, $\sigma$, the deviations from the average were calculated for the single measured chemocline levels and are shown in Tab. 2 .

The resulting $\sigma$ for 9 profiles is shown in Tab. 1 as the 'directly calculated' value. The calculation of $\sigma$ assumes a true stochastic distribution of the measurements. Since the resulting $\sigma$ for the average depth is of the same order of magnitude as the repeatability and the drift of the instrument, the 'directly calculated' $\sigma$ is probably slightly underestimated. The scatter in the single measurements is much larger than the drift and repeatability of the instrument would predict. This observation is believed to be mainly attributable to internal waves in the chemoclines, much in line with what has been reported by Schmid et al. (2004). The waves on the surface are believed to con-

Tab. 2. Deviation from the average of the measurements of chemocline levels from the single profiles (in $\mathrm{m}$ ).

\begin{tabular}{ccc}
\hline $191 \mathrm{~m}$ & $257 \mathrm{~m}$ & $313 \mathrm{~m}$ \\
\hline-0.38 & -0.20 & -0.20 \\
-0.70 & -0.09 & -0.31 \\
-0.07 & 0.00 & -0.39 \\
-0.41 & 0.03 & 0.42 \\
1.07 & 0.04 & -0.56 \\
0.12 & 0.19 & -0.05 \\
-0.20 & 0.17 & 0.18 \\
0.05 & -0.04 & 0.75 \\
0.53 & -0.08 & 0.16 \\
\hline
\end{tabular}

tribute to this uncertainty, but for a minor part only. This wave influence may be observed in Fig. 5, where at 67 and $115 \mathrm{~m}$ depth the two profiles show peaks at exactly the same level whereas in between these two levels, differences of 0.5 to $1 \mathrm{~m}$ between the peaks may be observed.

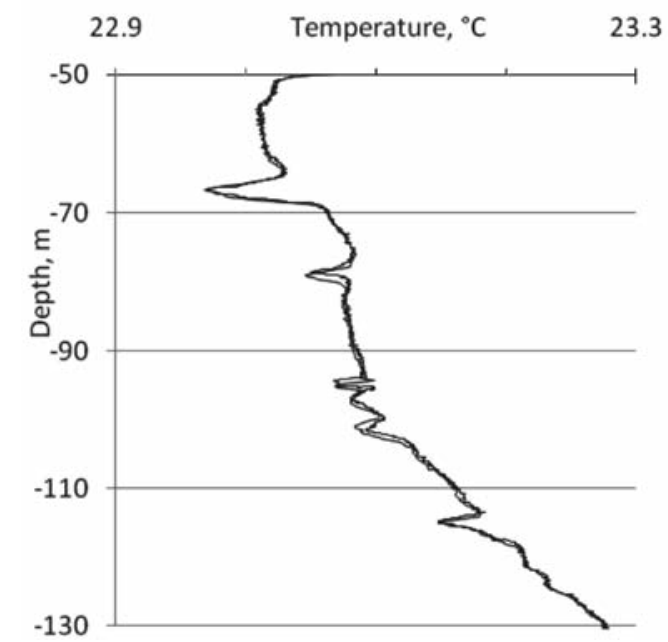

Fig. 5. Illustration of variation in temperature with depth between 50 and $150 \mathrm{~m}$ depth, showing both profiles from lowering and lifting of the instruments. Raw data provided by Umutoni et al. (2009a).

An impression of the uncertainties may also be gained from Fig. 2, where the dotted line is a single line representing Tietze's average of 23 profiles. Using the same line thickness, all 18 lines from the measurements of Umutoni et al. (2009a) have been drawn as solid lines so that what appears as one, thicker solid line in reality shows the scatter of the 18 single profiles.

Based on the above discussion of the errors in the 2009 readings of chemocline levels, it is considered probable that the average profile calculated by Tietze (1978) was subject to approximately the same accuracy as discussed for the 2009 results above, meaning that the average levels of the chemoclines are accurately determined. The resulting additional absolute error is estimated to be a maximum of 2 metres depth at any depth, whereas the relative errors (difference between two gradient levels from the same set of profiles) are believed to be significantly less, 0.5 to $1 \mathrm{~m}$. Therefore, the best possible estimate for the total uncertainty related to the measurements in Tab. 1 (in metres) is as shown in Tab. 3. The resulting estimate of $\sigma$ for the calculated difference between the 1975 and the 2009 levels thus is $=\sqrt{2 \cdot 1^{2}+0.6^{2}}=2.2 \mathrm{~m}$. 
Tab. 3. Estimate of total uncertainties in the determi-nation of chemocline levels (in $\mathrm{m}$ ).

\begin{tabular}{lccc}
\hline Year & 1975 & 2004 & 2009 \\
\hline Direct average & 0.2 & 0.6 & 0.3 \\
Variation in lake level & 0.5 & 0.5 & 0.5 \\
Numerical error (2004 profiles) & & 1 & \\
Graphical error (1975 profiles) & 2 & & \\
Total estimated $\sigma$ & 2.1 & 1.3 & 0.6 \\
\hline
\end{tabular}

The $191 \mathrm{~m}$ chemocline was higher in 2004 than in 2009 (Tab. 1). Given that most results confirm that the chemoclines are moving upward, this anomalous result should probably be taken as an indication of the true uncertainty in these attempts to measure the chemocline levels, but enhanced by 1) the fact that internal waves have the highest amplitude in this chemocline and 2) that only four profiles measured in 2004 were used for calculating the average and 3) the additional numerical error introduced by not having access to the raw data as explained above. Because of the uncertainties involved and because of these two sets of measurements being too close in time, one cannot expect conclusive results from a comparison between the 2004 and the 2009 measurements. A comparison of the 1975 and the 2004 results, on the other hand, confirms the results of Tab. 1, only with a slightly increased $\sigma$.

Because it is believed to be the oldest (single) profile on record of reasonable accuracy (Degens et al. 1973, Fig. 6), this Fig. has been read with the same degree of care as described above for the graphs of Tietze. Temperature profiles deviate more from the density profile than the salinity profiles (as noted above), and the error in deter-

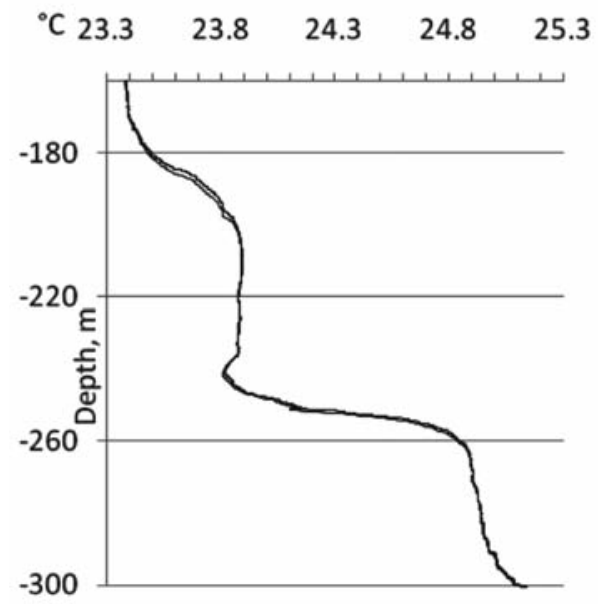

Fig. 6. Illustration of variation in temperature with depth between 160 and $320 \mathrm{~m}$ depth. Raw data provided by Umutoni et al. (2009a). mining the level of the centre of the density gradient has been estimated graphically (Tab. 1). The resulting chemocline levels are systematically on the low side as compared to later results warranting caution when interpreting these profiles. At a minimum, the results of Degens do not conflict with the deep chemocline levels measured by Tietze and they therefore provide additional support to the main result of this article: that the chemoclines have been moving upward over the last decades.

A new chemocline seems to be developing at a depth of $\sim 380$ to $\sim 400 \mathrm{~m}$ depth. This chemocline was identified in the same single temperature profile published by Degens et al. (1971, Fig. 5). This graph demonstrates a rather important vertical uncertainty allegedly due to recorder drift. The lowering profile gives an average of $\sim 390 \mathrm{~m}$ and the profile from the instrument upcast seems to show an average depth of this profile of $\sim 400 \mathrm{~m}$. The temperature profiles from 1975 published by Tietze were also rather imprecise, indicating that its centre was around 385 to $390 \mathrm{~m}$ depth. Finally, the average of four temperature profiles from 2004 as measured by Schmid et al. (2005) were the most precise of the three, giving a level of 384 $\mathrm{m}$ depth. Umutoni et al. have not measured profiles at such depth over the last years. Based on the Lahmeyer bathymetry, the largest probable upward movement $(400 \mathrm{~m}$ to $384 \mathrm{~m}$ ) corresponds to $\sim 2.3 \mathrm{~km}^{3}$ in 33 years or 0.07 $\mathrm{km} 3 \mathrm{y}^{-1}$. The smallest probable upward movement $(390$ $\mathrm{m}$ to $384 \mathrm{~m}$ ) corresponds to $\sim 1.0 \mathrm{~km} 3$ in 33 years or 0.03 $\mathrm{km}^{3} \mathrm{y}^{-1}$. The most likely result is therefore an upward movement in the range of 0.03 to $0.07 \mathrm{~km}^{3} \mathrm{y}^{-1}$.

Upward movement rates and inflows

After the above careful evaluation of the uncertainties, the estimated error margins shown in Tab. 1 are small enough to substantiate that the chemoclines in Lake Kivu are moving upward at three distinct levels. The error margins do indicate, however that there is a significant uncertainty related to the actual rate of upward movement (in $\mathrm{m} \mathrm{y}^{-1}$ ). Also at $390 \mathrm{~m}$ depth an upward movement has been detected.

If water of a different density flows into a (larger) body of water with a density stratification, the inflowing water will sink or rise until it reaches its isopycnal level. At this level it will spread out horizontally and mix into the surrounding larger body of water. As shown in figure 4 for Lake Kivu, this implies that the salinity of the water source must be approximately the same as in the lake at that isopycnal level, the measured upward movement of the chemoclines tells us, that such inflows do exist (see Section 4.1 below for further discussion). The level at which the water source is flowing into the lake, is independent of its final level of stratification. Based on the above results it is possible to calculate the sums of the deep water inflows that are required below each of the 
gradient levels to explain the measured upward movements.

1) One or more sources totalling approximately $<0.03$ to $0.07 \mathrm{~km}^{3} \mathrm{y}^{-1}$ (average value $\approx 0.05 \mathrm{~km}^{3} \mathrm{y}^{-1}$ ) have been flowing into the bottom of the lake, below $390 \mathrm{~m}$.

2) One or more sources totalling approximately 0.12 $\sim 0.05=\sim 0.07 \mathrm{~km}^{3} \mathrm{y}^{-1}$ have been flowing into the mixed layer between $313 \mathrm{~m}$ and $390 \mathrm{~m}$ depth;

3) A maximum of maybe some $0.130 .12=\sim 0.01 \mathrm{~km}^{3} \mathrm{y}^{-1}$ have been flowing into the mixed layer between 313 and $257 \mathrm{~m}$ depth.

4) One or more sources totalling approximately 0.25 $0.13=0.12 \mathrm{~km}^{3} \mathrm{y}^{-1}$ have been flowing into the mixed layer between 257 and $191 \mathrm{~m}$ depth.

Schmid, Busbridge, and Wüest (2010) have actually identified (one part of) this inflow from the negative temperature imprint seen on Fig. 6. These results are summarized in Tab. 4. It is likely that not one but a number of underwater sources contribute to give the total flow rates into each of the single mixed zones as calculated above. It is proposed to calculate the retention time in such a mixed layer as the time it takes for the centre of the chemocline right above that mixed layer to reach the level of $130 \mathrm{~m}$ depth. At this level, the upward moving chemocline together with the mixed layer below it will start merging into the uppermost chemocline because the latter is maintained in place as explained below. With this definition and assuming that gas extraction facilities do not interfere in the meantime, and that inflows remain unaltered with time, the time it takes before a mixed zone starts mixing into the uppermost chemocline is $\sim 1400$, $\sim 1100$ and 320 years respectively for the $313 \mathrm{~m}$, the 257 $\mathrm{m}$ and the $191 \mathrm{~m}$ chemoclines, respectively.

\section{DISCUSSION}

Observations of underwater inflows

Precipitation falls onto the lake directly and onto the ground in the catchment area. From the latter, water flows via rivers and through groundwater flow in sub-surface aquifers into the lake. The sub-surface flow is based on a ground water level sufficiently elevated above the surface of the lake to ensure the hydrostatic pressure necessary to sustain such flows. Apart from the evaporation at the sur-

Tab. 4. Summary of inflow rates determined in this article

\begin{tabular}{lc}
\hline Inflow level & Inflow \\
\hline Between $\sim 140$ and $191 \mathrm{~m}$ & $\sim 1.14 \mathrm{~km}^{3} \mathrm{y}^{-1}$ \\
Between 191 and $257 \mathrm{~m}$ (mainly at 220 and $245 \mathrm{~m}$ depth) & $\sim 0.12 \mathrm{~km}^{3} \mathrm{y}^{-1}$ \\
Between 257 and $313 \mathrm{~m}$ & $\sim 0.01 \mathrm{~km}^{3} \mathrm{y}^{-1}$ \\
Between 313 and $390 \mathrm{~m}$ (mainly at $350 \mathrm{~m}$ depth) & $\sim 0.07 \mathrm{~km}^{3} \mathrm{y}^{-1}$ \\
Below $390 \mathrm{~m}$ & $\sim 0.03$ to $~ 0.07$ \\
Total inflows below $\sim 140 \mathrm{~m}$ & $\approx 0.05 \mathrm{~km}^{3} \mathrm{y}^{-1}$ \\
\hline
\end{tabular}

face, it is these inflows that accumulate to whatever quantity is flowing from Lake Kivu via the Ruzizi River to Lake Tanganyika. Much more details on this water balance of the mixolimnion may be found in Muvundja et al. (2009). The rivers flowing into the lake are believed to be of low salinity. This is not systematically documented, but e.g. Degens et al. (1973) mention that the Lwiro and Kabindi creeks are almost 15 times less saline than the mixolimnion whereas a couple of hot springs (Kakondo and Kaukula) were of similar salinity as the mixolimnion.

In the light of these low salinity surface water inflows, the $\sim 1.08 \mathrm{~g} \mathrm{~kg}^{-1}$ salinity of Lake Kivu's mixolimnion (in 2004) is remarkable. A fraction of this salinity is annually exported via the Ruzizi River (Degens 1973; Muvundja 2009). This upward movement will add a corresponding amount of water to the mixolimnion, while the uppermost chemocline is eaten into from above by external forces such as currents, waves, shear, annual temperature overturns, and cold river inflows, as it may be seen in Fig. 5. In this way this chemocline is maintained in place (at level). On average, the largest fraction of the annual outflow of salts must be supplied by water moving upward through the uppermost chemocline from the salty mixed layer below. Degens et al. (1973) further wrote that the water inflows to Lake Kivu are assumed to be meteoric, meaning that they are assumed to vary in proportion to the annual net precipitation.

Based on the $\delta 180$ distribution and on the identification of one fumarole in the deepest part of Lake Kivu, Degens et al. (1973) suggested that hydrothermal vents at the bottom of the lake were likely to supply all the water and salt required to make up for the annual salt losses via the Ruzizi. The results in Tab. 4 now provide further information on this issue by establishing that fumaroles near the bottom of the lake may amount to only a few percent of the total water inflows. These are not as accurate as one might desire (Tab. 1). In spite of these measurement uncertainties, the low inflows of the densest water to the bottom of the lake have now been directly quantified for the first time, and the results are in contrast with the much higher numbers assumed earlier by Degens et al. (1971, 1973). The low salinity of hot surface springs and rivers is of no consequence for the conclusions; the measured upward movement of the chemoclines is only possible if water of sufficient high salinity flows into the mixed layer below a given chemocline.

A peculiarity in the catchment area of Lake Kivu is the fresh lava fields at the northern shores of Lake Kivu, marked by the absence of rivers as seen on maps (e.g., IRSAC 1959; Muvundja et al. 2009). It has been assumed that at this location, all precipitation seeps directly into the ground, dissolves salts underway and flows into the lake below the surface. This explanation is considered plausible, but it cannot be the full explanation, because 
this part of the catchment area is too small to provide an annual inflow of $1.39 \mathrm{~km}^{3}$ needed to supply all of the deep water sources (Tab. 4). It is therefore likely that waters of varying salinities flow into the lake from multiple locations around the lake, however with a significant fraction originating from near the northern shore and only a few percent coming up through the deep bottom as hydrothermal jets.

Based on the hydrostatic pressure from the ground water, the meteoric water will always flow along the path of least resistance. This may be through porous rock and through fissures that are plentiful in this rift zone. Earlier, it has been suggested (Tietze, pers. comm.; Kling et al. 2006) that the salts were being leached from the lava bed. This author suggests that an additional possibility is the 1 to $1.5 \mathrm{~m}$ thick tuff layer deposited between 11,000 and 12,000 years BP that was identified by Degens et al. (1973). This layer would constitute a path of lower resistance probably all around the lake, and it might at the same time serve as a source of leached salts to provide the annual inflow to the mixed zone between 330 and $380 \mathrm{~m}$ depth of $\sim 0.1 \mathrm{~km}^{3}$ of water of relatively uniform salinity.

\section{Cold surface water inflows}

The underwater sources mentioned in Section 4.1 are expected to be of the same temperature as the surrounding rock through which they flow. From observations in boreholes (Pollack, and Huang 2000) we know that the temperature of the upper crust of the earth increases steadily with depth (i.e., the geothermal gradient) from a surface temperature that is equal to the annual average temperature. Outside regions with increased magmatic activity, the average temperature profile typically lies between 15 and $25^{\circ} \mathrm{C} \mathrm{km}^{-1}$. Only in the upper part of the temperature profile, at some locations there is a low point of up to $0.5^{\circ} \mathrm{C}$ some $70 \mathrm{~m}$ down the hole, and this is attributed to global warming because at deeper levels the temperature profile has not yet had the time it takes to adapt to the slow downward spreading of the global warming. Under normal circumstances, at e.g. $250 \mathrm{~m}$ depth, the rock would be $\sim 3-5^{\circ} \mathrm{C}$ warmer than the surface, without considering any influence from the nearby Nyiragongo Volcano and its thermal anomaly. Thus, there is a significantly steeper temperature profile in the surrounding rock than in the lake itself. It is therefore not considered likely that low temperature water may come from water seeping deep through the rock and entering the lake at approximately the same level as the cold imprint is detected. Cold-water inflows are more likely to come from rivers or near-surface sources, much above the level of the cold imprint. Most of the underwater sources would be expected to be isothermal or warmer than the water in the lake. As examples, Degens et al. (1973) mention warm wells in the lake and so does a map from the Technip Study (1986) where warm water sources are shown to reach the surface of the lake a little to the south of Cape Rubona. Furthermore, Tedesco et al. (2010) mention several warm springs around Lake Kivu, testifying that hydrothermal circulation is active in the lake area.

In a separate campaign in 2009 , Umutoni et al. (2009b) followed the track of the Sebeya River from where it enters the lake in the outskirts of Gisenyi and sank into the lake down to a level of 90 to $105 \mathrm{~m}$ where, as it may be seen on Fig. 5, it gave rise to negative peaks on the temperature profile up to 3 kilometres from the point of inflow. This observation is also shown as the 'Sebeya track' (Fig. 1). Fig. 5 displays other such negative temperature peaks in the range from 60 to 130 and it appears likely that these peaks are the results of one or more river inflows to the lake relatively near the point of observation. Further away, these imprints are believed to disappear through horizontal mixing into the adjacent waters as also indicated by the temperature peak diminishing with distance from the estuary of the Sebeya River. Degens et al. (1973) also suggested that the dilution through horizontal mixing is related to double-diffusive convection. This phenomenon of dilution by rivers (of variable temperature and salinity) adds to the list of mechanisms that interfere with the uppermost chemocline in Lake Kivu, preventing it from moving upward together with the rest of the water body.

In the same way, negative temperature peaks permitted Tietze (1978) to conclude that water from the northwestern Kabuno Bay overflows via a narrow and shallow strait and spills into the main body of Lake Kivu, where it flows as an underwater river down the underwater slope of the main basin to eventually spread out at about $40 \mathrm{~m}$ depth and be distributed over a large part of the lake'. The salinity in the $12 \mathrm{~m}$ deep mixolimnion of Kabuno Bay $\left(\sim 1.5 \mathrm{~g} \mathrm{~L}^{-1}\right)$ is higher than in the main body of Lake Kivu $\left(\sim 1.1 \mathrm{~g} \mathrm{~L}^{-1}\right)$. At isothermal conditions, this salinity difference amounts to a density difference of $0.30 \mathrm{~kg} \mathrm{~m} \mathrm{3}$, corresponding exactly to the increase in in situ measured density by Tietze (1981) at that time and at a depth of $\sim 40$ $\mathrm{m}$. The water in the underwater river thus stopped at the first density barrier in the lake, a thermocline at $\sim 40 \mathrm{~m}$ depth. It is therefore suggested, that the overflow identified by Tietze was coming from the surface water in Lake Kabuno. It is furthermore suggested, that such outflow happens especially during periods with northerly and westerly winds that lower the surface level of north-westerly Lake Kivu and therefore cause outflows of surface waters from Kabuno Bay into the main basin of Lake Kivu. On average, these outflows must correspond to the net inflows from rivers into Kabuno Bay. This flow at the same time represents a net export of salts from Kabuno Bay to the main basin of the lake, meaning that there must be a continuous source of salts to make up for these losses. 
Upward movement through the uppermost chemocline

For proper calculations of mass balances in the lake it is also necessary to know, how much water is injected into the mixolimnion from below. Like with the lower chemoclines in the lake the body of water at the level of this uppermost chemocline is also moving upward and at a much higher rate (in $\mathrm{km}^{3} \mathrm{y}^{-1}$ ) than the other chemoclines. However, unlike the other chemoclines, the uppermost chemocline remains in place (Fig. 2). This also means, that unlike the other chemoclines, mass is moving upward across this uppermost chemocline.

An estimate of this upward movement across the uppermost chemocline may be calculated assuming efficient mixing in the mixolimnion. The average salt concentration (from Schmid et al. 2005) in the mixed zone right below the mixolimnion of $2.59 \mathrm{~g} \mathrm{~L}^{-1}$ may be compared with the salt concentration in the mixolimnion of $1.08 \mathrm{~g}$ $\mathrm{L}^{-1}$. A recent estimate of the outflow via the Ruzizi River of $3.6 \mathrm{~km}^{3} \mathrm{y}^{-1}$ has been provided by Muvundja et al. (2009). These data allow to establish an updated water balance for the mixolimnion:

$$
\begin{aligned}
3.6= & Q_{\text {Ruzizi }}=Q_{\text {rain }}+Q_{\text {rivers }}-Q_{\text {evaporation }}+Q_{\text {upward movement }} \\
= & Q_{\text {net surface input }}+Q_{\text {upward movement }}\left(\mathrm{km}^{3} \mathrm{y}^{-1}\right)
\end{aligned}
$$

As well as a salt balance:

$$
1.08 \mathrm{Q}_{\text {Ruzizi }}=2.59 \mathrm{Q}_{\text {upward movement }}\left(10^{6} \mathrm{t} \mathrm{y}^{-1}\right)
$$

where $\mathrm{Q}_{\text {upward movement }}$ is the average yearly total upward flow rate at $130 \mathrm{~m}$ depth, injecting salts into the mixolimnion. Since $\mathrm{Q}_{\text {Ruzizi }}=3.6 \mathrm{~km}^{3} \mathrm{y}^{-1}$, it follows from Eq. 2 that the total of the deep-water inflows (below 140 $\mathrm{m}), \mathrm{Q}_{\text {upward movement }}=1.50 \mathrm{~km}^{3} \mathrm{y}^{-1}$. Eq. 1 then gives the net inflow of low salt surface water, $Q_{\text {net surface input }}=3.6-1.5=2.1$ $\mathrm{km}^{3} \mathrm{y}^{-1}$. This simple water balance has also been made by others (e.g., Pasche 2009).

The saline inflow from the mixolimnion in Kabuno Bay should also be taken into consideration. From $\mathrm{Mu}-$ vundja et al. (2009) the sum of river inflows to Kabuno Bay may be estimated to $6 \mathrm{~L} \mathrm{~s}^{-1}$ or $0.19 \mathrm{~km}^{3} \mathrm{y}^{-1}$. For simplicity, since these parameters are not yet known, we will assume that like for the entire Lake Kivu, the upward movement in Kabuno Bay plus the precipitation onto the lake is equal to the evaporation so that the inflow from the rivers equals the outflow from the mixolimnion in Kabuno Bay to the mixolimnion in Lake Kivu. With this assumption, Eq. 2 is expanded to:

$1.08 \times 3.6=2.59 \mathrm{Q}_{\text {upward movement }}+1.5 \times 0.19\left(10^{6} \mathrm{t} \mathrm{y}^{-1}\right)$

This gives a slightly reduced sum of inflows below $130 \mathrm{~m}, \mathrm{Q}_{\text {upward movement }}=1.39 \mathrm{~km}^{3} \mathrm{y}^{-1}$. Eq. 1 therefore gives a slightly increased value for the net inflow of low salt surface water, $Q_{\text {net surface input }}=3.61 .39=2.2 \mathrm{~km}^{3} \mathrm{y}^{-1}$. Furthermore, section 3.2 has established that at the level of the $191 \mathrm{~m}$ chemocline, only $\sim 0.25 \mathrm{~km}^{3} \mathrm{y}^{-1}$ are moving upward. This means that a large flux of water $=1.39$ $0.25=1.14 \mathrm{~km}^{3} \mathrm{y}^{-1}$ must be flowing into the lake and end up in the mixed zone right below the upper chemocline, at a level between 130 and $191 \mathrm{~m}$ depth. This result is also shown in Tab. 4.

The calculated value for $\mathrm{Q}_{\text {upward movement }}$ should be considered a bit on the high side because it does not take into consideration possible other inflows of salts with the rivers or via warm and possibly saline hydrothermal vents into the mixolimnion and it also assumes that a steadystate salt concentration has been established. The latter is not necessarily quite true because of the years with much rain in the 60'ies. Degens et al. (1973) mention warm, saliferous springs in the catchment area of Lake Kivu as additional sources of saline inflows to the mixolimnion. In spite of this uncertainty, it seems likely that a natural inflow takes place of the water in the mixed zone between 130 and $191 \mathrm{~m}$ depth.

Dilution in the mixed zone above $191 \mathrm{~m}$

This inflow of water to the mixed zone right below the mixolimnion, as calculated above, will cause dilution of the methane gas trapped in this zone. In this zone, the total gas pressure may never be allowed to increase so much that the resulting bubble volume in an extraction pipe may be expected to overcome the technological pressure drops in the extraction equipment at feasible flow rates. Furthermore, the energy in the methane extracted would hardly suffice for operation of the gas treatment and handling facilities. Yet one must expect that gases have been and are accumulating in this zone as well, apparently calling for accumulating gas also to be removed from this zone. It is possible however, that the important inflow to this zone of the gas-diluting water sources that has now been detected (as a difference between two measured upward flow rates) may serve to dilute this zone so much that gas accumulation perhaps might be prevented from reaching critical levels, all by this mechanism of natural dilution.

That no methane accumulation could be detected from 1975 to 2004 (Schmid et al. 2005) might indicate just that. But the result is yet uncertain and further monitoring is required to reach a firm conclusion.

\section{Upward movement of water from Kabuno Bay}

The mechanisms behind the upward movement of saline water in the main body of Lake Kivu described above are also assumed to take place in Kabuno Bay. The same lava plains believed to be a significant salt source for the deep saline inflows to the main body of Lake Kivu also border Kabuno Bay. Over long time spans, it would not be possible to maintain a chemocline as flat and as close to the surface as the one below $12 \mathrm{~m}$ depth in Kabuno Bay without significant upward movement.

Dense upward moving water $\left(1000.7 \mathrm{~kg} \mathrm{~m}^{-3}\right)$ is assumed to spill into the main basin at times when the wind 
conditions are right, mainly during times with southerly and westerly winds, where it should be easy for wind-induced underwater movements to temporarily displace the chemocline upward by more than what is necessary to allow denser monimolimnion water to flow through the strait when winds are in the right direction.

If it remains unmixed, the cool and heavy water from Kabuno Bay would have sufficient density to flow down the underwater slopes and into the upper part of the 257 $\mathrm{m}$ chemocline. At this level it would then spread out and mix with the surrounding water in the lake, leaving a negative temperature anomaly at that level. The above description implies a dilution of the inflow at that level, increasing with distance from the point where the isopycnal level is reached. The report by Tietze (1978), that a negative temperature signal was traceable 'over a large part of the lake' may also indicate that the signal disappeared farther away, given that the 23 profiles measured were well distributed all over the lake. Another more direct indication of this behaviour may be found in the results of Umutoni et al. (2009b).

Such a negative temperature anomaly has been observed in nearly all accurately measured temperature profiles in the northern part of Lake Kivu (Halbwachs et al. 2002; Schmid et al. 2005, and Fig. 6). They all show an intrusion of a cold water source, stratifying at the level of $\sim 245 \mathrm{~m}$ depth. The fact that the temperature imprint has been detected at $\sim 245 \mathrm{~m}$ depth indicates that a moderate dilution with the surrounding water has taken place on the $\sim 6$ kilometres it takes for this under-water river to travel from Kabuno Bay to this depth of the main lake, presumably following rather closely the western shoreline as would be predicted from the bathymetry of the lake (Lahmeyer, and OSAE 1998). This inflow also disturbs the normal double-diffusive shape of the upper part of this chemocline. Without this disturbance we might have expected a gradational transition from the mixed zone to the chemocline as is the case for the two other undisturbed chemoclines in the deeper parts of the lake.

It is apparent that not one but two alternating underwater rivers overflow from Kabuno Bay: under one set of wind conditions it is the lighter underwater river from the Kabuno Bay mixolimnion, stratifying into the mixolimnion of the main basin in Lake Kivu; under another set of wind conditions it is the denser underwater river of upward moving water from the Kabuno chemocline flowing down to reach and restratify at the top of the main chemocline around $245 \mathrm{~m}$ depth. This also implies that this denser underwater river from Kabuno Bay contributes to the upward movement of the $191 \mathrm{~m}$ chemocline.

Padman, and Dillon (1987) have suggested that the time it takes for diffusive layering to erase a perturbation and to reestablish the double-diffusive cell structure anew is of the order of one month. This would explain why traces of cold small river intrusions may be found in one profile but not in another. Such temperature anomalies disappear with time in a diffusively layered system. Only large and lasting sources such as the dense underwater river inflow to $\sim 245 \mathrm{~m}$ depth are of such magnitude and persistence that it may be traced over larger parts of the main basin.

Schmid et al. (2010) plot the density ratio, $R \rho$, as a function of depth, where this parameter is defined (Turner 1973) as the ratio between the stabilizing density component and the destabilizing density component in doublediffusive convection:

$$
R_{\rho}=\frac{\beta \partial S / \partial z}{\alpha \partial T / \partial z}
$$

$R \rho$ usually varies between 2 and 3 in the mixed zones, increasing to 4 to 7 in the main chemoclines. But at three levels in the lake ( $\sim 220, \sim 245$ and $\sim 350 \mathrm{~m}$ depth), this number increases to well above 10 . Since this density ratio depends on the salinity and the temperature profile in the lake, these high numbers reflect anomalies, because in a double-diffusively layered system in quasi steady state such jumps in $R \rho$ cannot exist (Hirslund 2012, submitted). These anomalies likely represent the signatures of water inflows, stratifying at these levels in the lake and dispersing laterally. This is consistent with the results in Tab. 4 and two of the levels ( $\sim 245$ and $\sim 350$ m depth) also match with identified cold temperature anomalies.

Threats posed by upward movement of the chemoclines

If the annual precipitation does not change, the inflows of saline water described above would continue at the same rate as over the last 34 years and, together with the gas laden zone below it, the $191 \mathrm{~m}$ chemocline will continue to migrate upwards to reach the $130 \mathrm{~m}$ level in approximately 300 years. By this time, gases may have accumulated further so as to be close to saturation at this new elevation. This would mean that a relatively minor triggering event (of relatively low energy release) could cause a limnic eruption from this mixed zone that is presently located between the $191 \mathrm{~m}$ and the $257 \mathrm{~m}$ chemoclines. This would happen even if all the accumulated gas from the lower and commercially attractive zones has been removed.

The technical feasibility limit of gas extraction from the lake depends on sufficiently high gas concentrations to provide the pumping effect that lifts the gasladen water to the surface and forces it back down again to depth. There must be enough pressure-drop available to overcome resistance to flow in the gas extraction equipment. The technical feasibility limit is also set by the methane yield from the produced gas which must be sufficient to generate the power needed to operate the ancillary sys- 
tems in the gas extraction facility. The resulting limit to technical feasibility may be expressed as a total necessary minimum pressure of the dissolved gases in the lake stratum concerned. This gas availability is an absolute number that does not depend on the depth from which the water is extracted. This limit is illustrated as a vertical line in Fig. 7.

Lorke et al. (2004) pointed to the risk of massive lava inflow to the lake, causing a premature eruption of the dissolved gases. Other triggers are also conceivable. The risk that such a trigger event is large enough to induce premature limnic eruption depends on the relative pressure of the dissolved gases, expressed as a percentage of the hydrostatic pressure. A preliminary estimate suggests that at all levels in the lake this limit of acceptability might be around $40 \%$.

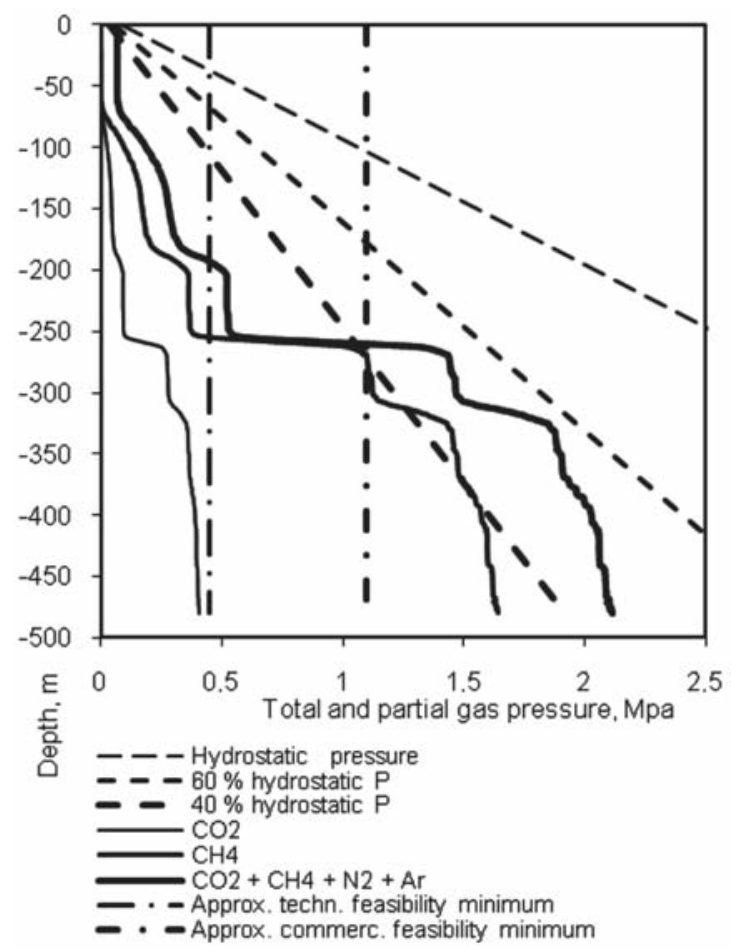

Fig. 7. Illustration of the principles that apply to technical and economical feasibility limitations to gas extraction as well as approximate estimates of their magnitude. The thin vertical line represents approximate limit of technical feasibility. The thick vertical line represents approximate limit of commercial feasibility. The intersections between the following lines have the following significance:

- technical feasibility and $40 \%$ hydrostatic pressure: maximum theoretical level below which long-term safe gas extraction might be technically possible;

- technical feasibility, and total gas pressure: Maximum actual level below which safe gas extraction is technically possible at present;

- economic feasibility, and $40 \%$ hydrostatic pressure: maximum limit to safe and economically feasible gas extraction.
These relationships are also illustrated in Fig. 7 where the hydrostatic pressure as well as the present $60 \%$ limit and a notional future $40 \%$ limit are shown. Also plotted are the 2004 gas pressures from Schmid et al. (2005) as a function of depth, however slightly updated to also include the pressure from the dissolved inert gases N2 and Ar. When considering both technical feasibility and public safety, there are well defined limits in which gas extraction is feasible while maintaining the risk of a limnic eruption at an acceptably low level. The notional theoretical limit for feasible gas extraction lies at the intersection between the vertical technical feasibility line and the $40 \%$ relative gas pressure line. The location of this line is based on the most efficient gas extraction technology known to date (Morkel, pers. comm.). This intersection also translates to an upper depth limit for the acceptable migration of the $191 \mathrm{~m}$ chemocline. Based on the capabilities of existing gas extraction facilities, it may be estimated that this theoretical upper limit to technical feasibility would be reached if the $191 \mathrm{~m}$ chemocline were to be allowed to rise to around $130 \mathrm{~m}$ below the surface.

In order for gas extraction plants to materialize as our tool to prevent limnic eruptions, it must also be commercially viable. This requires a certain minimum total gas pressure to give minimum gas production and thus a power production rate that gives an acceptable pay-back time. This limit has also been approximately indicated as a vertical line on Fig. 7. The precise location of this line on the $\mathrm{x}$-axis is less certain because it depends on the actual extraction and conversion technology as well as on fluctuating energy prices. The location of this commercial feasibility limit is estimated from current data but will vary with time. Experience with commercial lake gas extraction plants will allow provision of a more accurate estimate. Where the vertical line for commercial viability intersects with the $40 \%$ relative gas pressure line, lies the notional maximum level above which commercial gas extraction would never become viable. This is the limit if long-term risk levels are to be kept at an acceptably low level corresponding to $40 \%$ saturation.

At present gas extraction from the 191 to $257 \mathrm{~m}$ zone is not believed to be commercially viable, and if the density gradients were allowed to migrate upward we would probably soon loose even the technical feasibility. It is therefore important not to let the situation worsen through further upward movement. If we want to use gas extraction to maintain controllability over the gas accumulation in this zone, it is necessary to prevent the 191 and the 257 $\mathrm{m}$ gradients from moving upward any further, in anticipation of future commercial viability. If the $191 \mathrm{~m}$ chemocline were to well up much further, we may soon have irreversibly (within a couple of decades) lost the only realistic tool for the more comprehensive preservation of public safety around Lake Kivu. It is therefore now that 
the commercial gas extraction facilities of our generation must be adapted to meet this challenge if we want to preserve the lake shores as a safely habitable place for the future generations.

Furthermore, gas extraction gas extraction from the 191 to $257 \mathrm{~m}$ zone is technically quite challenging and this challenge increases if the $191 \mathrm{~m}$ and the $257 \mathrm{~m}$ chemoclines become closer together. Preservation of the technical feasibility of gas extraction from this zone and thus prevention of a future limnic eruption demands that both chemoclines are maintained in their current positions.

Should we lose gas extraction as the tool to curb gas accumulation in Lake Kivu, venting plants would be the only option left. The direct degassing of methane to the atmosphere in venting systems would cause a regrettable emission of significant quantities of greenhouse gas to the atmosphere. Also, it would represent a loss of a large renewable energy source to society, and it would also result in the eutrophication of the lake and its ensuing deleterious effect on the fish production. Furthermore, venting plants are costly, running up to hundreds of millions of dollars, and unlike commercial gas extraction which generates revenue allowing recovering the costs of safety preservation, it appears risky to assume that funding sources could be found for such massive investment in safety by venting plants. It took more than 10 years after the eruption of Lake Nyos to collect enough funds to prevent a new eruption of this lake, and this investment was well below 1/100th of the investment in gas venting plants that would be required in Lake Kivu.

\section{An earlier assumption}

Here I show that the chemoclines are moving upwards. This situation involves an increasing risk of a future limnic eruption becoming unstoppable if it is allowed to last for long; it is necessary to concentrate on how to avert the resulting danger. Since 2005, the assumption of chemoclines remaining at a fixed level is systematically used by EAWAG in their works on Lake Kivu although it is sometimes not even mentioned as an assumption as is e.g. the case in Wüest, Jarc, and Schmid (2009). This is the reason why it was considered necessary to take the perhaps unusual step at this place to demonstrate that no foundation exists for the theory published by Schmid et al. (2005).

The upward migration of the chemoclines is possible because dense water flows into the lake at levels below the chemoclines. Their ability to move up or down, without this movement causing any disturbance to their shape, has been observed in Cameroon. Immediately following the limnic eruptions in lakes Nyos and Monoun, the chemoclines rose while maintaining their shape (see e.g., Evans et al. 1993). After the onset of degassing, the shapes of the chemoclines were preserved while being drawn down by the venting facilities (downwelling) (see Halbwachs et al. 2004 and Schmid et al. 2006). Thus, the vertical migration of chemoclines while preserving their shape is well documented in other systems and is not unique to Lake Kivu.

Schmid et al. (2005) rightfully asked the question: How may it be that the chemoclines in Lake Kivu exist in the form of a large-scale staircase with 5 steps and that the chemoclines are not destroyed by external forces? Some mechanism is required to form and to maintain the gradients as sharp as they are. Schmid et al. (2005) postulated that the gradients are sustained by water inputs (flowing in and remaining at fixed depths). According to this hypothesis, inflows of colder, less saline, and lighter water at fixed levels should be the reason for formation and maintaining the shape of the chemoclines through dilution of the body of water that is being pushed up by the deep water inflow, thus preventing the chemoclines from moving upward together with the rest of the water body.

One argument against this dilution assumption is that, the measured shape of the chemoclines is nearly symmetrical around its central point (Fig. 4), and the inflow of water at a fixed point above the chemocline cannot account for the shape of the gradient below the central point. Apart from the deviations from the steady-state shape caused by waves and the underwater river at $245 \mathrm{~m}$ as discussed above, all profiles measured in Lake Kivu display such approximate point symmetry around the centre of each chemocline in the diffusively layered lower part of the lake. Another argument against this assumption is that whilst Fig. 6 clearly shows a cold-water intrusion influencing the temperature profile at $\sim 245 \mathrm{~m}$ depth, the same Fig. shows no sign of similar intrusions at $180 \mathrm{~m}$ and 300 $m$ depths.

Further, it may be observed that in the explanations provided by Schmid et al. (2005), the inflow rates should have been as shown in Tab. 5 in order to explain the mass balances related to their proposed assumption. The difference between the inflows at $250 \mathrm{~m}$ and below $315 \mathrm{~m}(0.47$ $\left.0.12=0.35 \mathrm{~km}^{3} \mathrm{y}^{-1}\right)$ is crucial for their assumption. As explained above, due to the surface level of the lake not being measured in 1975 there might be a larger absolute uncertainty on the inflows calculated in this article $(0.13$ and $0.12 \mathrm{~km}^{3} \mathrm{y}^{-1}$ to the different levels of the lake), but the uncertainty on the difference between these two numbers in the same year is only around 0.5 to $1.0 \mathrm{~m}$ or around \pm 0.01 to $0.02 \mathrm{~km}^{3} \mathrm{y}^{-1}$ - out of a measured difference of $0.13 \mathrm{~km}^{3} \mathrm{y}^{-1}$. This result leaves no room for a difference of $0.35 \mathrm{~km}^{3} \mathrm{y}^{-1}$ that would be required for the 2005 assumption to be valid.

Schmid et al. (2003) used a 1-dimensional model based on the $\kappa-\varepsilon$ model for turbulent diffusion to describe vertical mass transport in the lake. As per Osborn (1980) 
Tab. 5. Inflow rates essential for constant chemocline position as proposed by Schmid et al. (2005).

\begin{tabular}{lc}
\hline Inflow level & Inflow \\
\hline Below $315 \mathrm{~m}$ & $0.12 \mathrm{~km}^{3} \mathrm{y}^{-1}$ \\
At $315 \mathrm{~m}$ & $0.03 \mathrm{~km}^{3} \mathrm{y}^{-1}$ \\
At $250 \mathrm{~m}$ & $0.47 \mathrm{~km}^{3} \mathrm{y}^{-1}$ \\
Difference between $315 \mathrm{~m}$ and $250 \mathrm{~m}$ & $0.35 \mathrm{~km}^{3} \mathrm{y}^{-1}$ \\
\hline
\end{tabular}

this use of the $\kappa-\varepsilon$ model is questionable for a diffusively layered body of water such as Lake Kivu as double diffusive phenomena are not included (see also Huppert, and Turner 1981). An important and central assumption of the 1-dimensional model is that once introduced into the lake at a certain level, any water from that source would remain at this level, irrespective of density differences between the lake and the source (pers. comm. from EAWAG, Oct. 2007). The model thus calculates that such a source will remain at that level, mixing with and diluting' water mowing upward, thereby maintaining the chemocline in place. Thus, the finding that the water intrusions remain at a fixed depth (Schmid et al. 2010) is simply an artefact specified in the underlying model. If one wants to create a density difference by using a source of water to dilute a denser body of water welling up from below, the source required to generate such dilution must be significantly lighter. If this is so, all physical evidence tells us, that such a source will flow upward because it is lighter, it will not remain at the same level. Also, there is insufficient linear velocity to cause any significant mixing with the surrounding water at the level of entry. If, on the other hand the source is not lighter but of equal density, then it may well remain at level and mix into the surrounding water at that level, but then there can be no density difference to create a pycnocline.

\section{Prevention of upward movement and its consequences}

The maintenance of the chemoclines in their current positions is technically possible. It is easy to use a fraction of the future gas extraction facilities to achieve this. Approximately $0.13 \mathrm{~km}^{3} \mathrm{y}^{-1}$ must be extracted from $300 \mathrm{~m}$ depth or deeper and additionally $0.12 \mathrm{~km}^{3} \mathrm{y}^{-1}$ must be extracted from $250 \mathrm{~m}$ depth and in both cases the degassed water must be disposed of so as not to sink past the uppermost chemocline, thus remaining in the mixolimnion. This will have potentially some environmental consequences because of the high phosphorous content in this water. There are two possible options for the disposal of this water: 1) to dispose of it directly into the Ruzizi River, which would be deleterious to the river ecology, cause the river banks to become uninhabitable due to the $\mathrm{H} 2 \mathrm{~S}$ emanating from the water, and transfer the enhanced nutrient flux to Lake Tanganyika, or 2) to dispose it into the mixolimnion of Lake Kivu, where this injection of phosphorous would give rise to additional algal growth.
Disposing the water to the Ruzizi River would be very expensive and technically very challenging, balancing on the verge of technical impossibility. Disposal to the local mixolimnion would give rise to both enhanced fish stocks and to oxygen depletion. An estimate of the resulting additional P-inflow to the mixolimnion is therefore presented below. Also, remaining traces of hydrogen sulphide and of methane would be oxidised to harmless sulphate and to the much less problematic carbon dioxide while the increased algal growth would result in increased methane production in the lake.

Pasche (2009) has established that in unique Lake Kivu, the upward transport of phosphorous accounts for about $90 \%$ of the annual input to the mixolimnion, whereas river inflows and atmospheric precipitation account for about $10 \%$. Here, $\mathrm{P}$ is limiting phyto-plankton growth. A slight reduction in this estimate of upward $\mathrm{P}$ transport results from section 4.3 above, but it does not change the fact that the single most significant input of phosphorous stems from upward transport. Significant variations exist in the depth to which annual temperature overturns together with other mixing mechanisms penetrate into the chemocline below the mixolimnion. As a result, significant variations in the upward transport of phosphorous and thus in peak algal growth are expected from year to year. But on average over several years, the discharge of phosphorous to the mixolimnion may be estimated from the yearly upward movement rate multiplied by the P-concentration in the mixed zone below. With the concentrations from 2004 (Schmid et al. 2005), this gives an annual upflow of $\sim 57 \mathrm{Mmol} \mathrm{y}^{-1}$ into the mixolimnion (Tab. 6).

The proposed injection of part of the extracted water from the gas extraction facilities into the mixolimnion, would cause additional transport of $23+8=31 \mathrm{Mmol} \mathrm{P} \mathrm{y}^{-1}$ into the mixolimnion. However, the average contribution from the annual upward movement would also be reduced by $10 \mathrm{Mmol} \mathrm{P} \mathrm{y}^{-1}$ (due to the resulting reduction in the natural upward movement), corresponding to a net in-

Tab. 6. Calculated difference in inputs of phosphorous to the mixolimnion in the present situation and in a future situation with prevention of chemocline upward movement.

\begin{tabular}{lccc}
\hline & $\begin{array}{c}\text { Water } \\
\text { flow rate } \\
\left(\mathrm{km}^{3} \mathrm{y}^{-1}\right)\end{array}$ & $\begin{array}{c}\text { P conc. } \\
\left(\mu \mathrm{mol} \mathrm{L} \mathrm{L}^{-1}\right)\end{array}$ & $\begin{array}{c}\text { P inflow } \\
\left(\mathrm{Mmol} \mathrm{y}^{-1}\right)\end{array}$ \\
\hline $\begin{array}{l}\text { PRESENT-DAY SITUATION } \\
\text { Upward movement into mixolimnion }\end{array}$ & 1.39 & 42 & 57 \\
$\begin{array}{l}\text { FUTURE EQUILIBRIUM } \\
\text { SITUATION }\end{array}$ & & & \\
$\begin{array}{l}\text { Water from bottom } \\
\text { Water from 250 m depth }\end{array}$ & 0.13 & 180 & 23 \\
$\begin{array}{l}\text { Reduced upward movement } \\
\text { (from 140 m) }\end{array}$ & 0.12 & 65 & 8 \\
Net additional input into mixolimnion & -0.25 & 42 & -10 \\
\hline
\end{tabular}


crease by $3110=21 \mathrm{Mmol} \mathrm{y}^{-1}$ or $\sim 21 / 57 \approx 37 \% \mathrm{P}$ to the mixolimnion. Based on simulations of plankton production, Darchambeau (2011) has indicated that an additional input of $\sim 10,000 \mathrm{tP} \mathrm{y}^{-1}\left(=320 \mathrm{Mmol} \mathrm{y}^{-1}\right)$ could constitute an approximate upper limit to what input of phosphorous to the mixolimnion of Lake Kivu does not cause a major impact. The proposed additional load from prevention of gradient moving upward is only $1 / 12^{\text {th }}$ of this upper limit. In addition to the stipulations in Boyle et al. (2009), the concessionaires could, on a proportional basis, therefore discharge a fraction of the degassed water directly into the mixolimnion as described so as to outbalance the upward movement and make the chemoclines remain approximately at today's levels.

An additional impact is that of oxygen depletion and the toxicity of the hydrogen sulphide. There are in principle two ways of injecting the degassed water to the mixolimnion.

1) If injected so as to accumulate at the bottom of the mixolimnion, it would remain there until the annual temperature-induced mixing of the mixolimnion, at which time it would add to the yearly peak algal bloom lasting for some weeks.

2) If injected so as to mix into the oxygenated part of the mixolimnion it will locally create dead zones, toxic to fish, but the resulting algal growth would be spread over the year and is therefore expected to be of much less significance.

Further studies should address which of these two options would cause the least damage to the environment.

In this context it is worth mentioning, that there have been proposals to degas the monimolimnion of Kabuno Bay. The method would be much the same as in the case of lakes Nyos and Monoun, spilling the degassed water onto the surface of the lake. If this is done in such a way as to ensure mixing with the mixolimnion and not only sinking back into the monimolimnion of Kabuno Bay, it would result in increasing the flow rate of the lighter underwater river that mixes into the mixolimnion of the main lake. This would simultaneously reduce or may be even eliminate the denser underwater river stratifying at $\sim 245 \mathrm{~m}$. In this way it would remove or reduce one known source behind the upward movement of the $190 \mathrm{~m}$ chemocline and thus reduce somewhat the problems caused by upward movement of the gradient. Flow rates are not known, but such degassing of Kabuno Bay would definitely be beneficial also to the main lake. As fish are absent in Kabuno Bay, the resulting oxygen depletion in Kabuno Bay from such venting is believed to be of no major consequence to the ecology of the lake.

\section{CONCLUSIONS}

Saline water sources flow into the lake and restratify at their isopycnal levels, then dispersing horizontally and mixing into the different mixed zones below the chemoclines. Below $190 \mathrm{~m}$, this mainly happens near depths of $350 \mathrm{~m}, 220 \mathrm{~m}$ and $245 \mathrm{~m}$. These inflows are apparent from the upward migration of the chemoclines which has been quantified here for the first time. These upward flow rates can be used to calculate inflow rates. The uppermost chemocline is an exception, because it remains in place due to mixing from above. Salts are transported through this uppermost chemocline resulting in a relatively high salinity of the mixolimnion. From the salt balance, it is possible to estimate this salt transport.

The partitioning of inflows from different sources with their inherent density and salinity sheds additional light on the water balances in Lake Kivu. The dense inflows through the very bottom of the lake play a minor role only. Cold rivers have been identified, which sink to and mix into the uppermost chemocline in the lake. Due to their limited salinity, however, they are not dense enough to sink further. Due to of the geothermal gradient, cold water inflows can only come from the surface or near the surface of the lake, such as the Sebeya River, which sinks to around $100 \mathrm{~m}$ depth.

The (cold) inflows from the Kabuno Bay constitute a case of their own. Depending on wind direction, either a relatively low density current flows from the mixolimnion of Kabuno Bay, to the level of the first thermocline or, the much denser Kabuno Bay monimolimnion is pushed up, flowing into the shallow strait and down the bottom slope to disperse horizontally into Lake Kivu at $245 \mathrm{~m}$ depth and causing a negative temperature anomaly which has been measured on several occasions. Upward movement of gas bearing zones brings them closer to the surface, causing the relative gas pressure to increase and diminishing the energy necessary to cause a limnic eruption. This effect is enhanced by an assumed gas accumulation in most zones. Therefore, the probability of a limnic eruption increases with time, especially in the zone presently between 190 and $257 \mathrm{~m}$ depth, because gas extraction from this zone might not start in time because of lack of commercial feasibility. A further complication is that if these two chemoclines should be allowed to lift much further, it might never become economically feasible to extract gas from this zone. The consequences of running this risk are such that further upward movement should be prevented soonest. This could be accomplished by discharging around $0.25 \mathrm{~km}^{3} \mathrm{y}^{-1}$ of degassed water into the biozone. This would result in additional algal growth and thus increased fish and gas production (in the deeper strata).

According to an assumption from 2005, the chemoclines would not be pushed up even if the rest of the water body around it was recognised to do so. This assumption has been in the way of agreeing on the above appropriate measures to take against chemoclines moving upward, 
and it has therefore been carefully evaluated with the result that it has been found not to hold. This has removed the last shred of doubt as to the reality of the upward movement and allows us to concentrate on preventing further upward movement and through that prevent a future limnic eruption from the lake.

\section{ACKNOWLEDGMENTS}

The author wishes to thank A. Umutoni, A. Mugisha, T. Nzayisenga, and L. Rwandekwe from the Ministry of Infrastructure, Kigali, Rwanda for providing the raw data used in this article. I further want to thank C. Jürgensen for indepth discussions, A. Jacobsen for his suggestions and P. Skirl and J. Steenfelt for a review of the language as well as J. Emborg who assisted with certain calculations. Finally, I want to thank Sean Crowe for many good suggestions and the four unknown referees for many inspiring and useful comments.

\section{REFERENCES}

Boyle J, Hirslund F, Morkel P, Schmid M, Tietze K, and Wüest A. 2009. Management Prescriptions for the development of Lake Kivu gas resources. Document prepared for the Ministry of Infrastructure, Rwanda and Ministry of Hydrocarbons, D.R. Congo.

Damas H. 1937. La stratification thermique et chimique des lacs Kivu, Edouard et Ndalager (Congo Belge). Verh. Int. Ver. theor. u. angew. Limnol. 8: 51-68.

Darchambeau F. 2011. Potential impacts of methane extraction on lake ecosystem. Presentation at international workshop on the monitoring and development of Lake Kivu gas resources, Gisenyi, Rwanda, from 8th to 10th of February, 2011.

de Benedetti AA, Funicielo R, Giordano G, Diano G, Caprilli A, and Paterne M. 2008. Volcanology, history and myths of the Lake Albano maar (Colli Albani Volcano, Italy). J. Volcanol. Geotherm. Res. 176: 387-406. doi:10.1016/j.volgeores.2008.01.035

Degens ET, von Herzen RP, Wong HK, Deuser WG, and Jannasch HW. 1973. Lake Kivu: Structure, chemistry and biology of an East African Rift Lake. Geol. Rundsch. 62: 245-277.

Degens ET, Deuser WG, von Herzen RP, Wong HK, Wooding FB, Jannasch HW, and Kanwisher JW. 1971. Lake Kivu expedition: Geophysics, hydrography, sedimentology (preliminary report). Unpubl. Woods Hole Oceanographic Institution, ref. 71-52.

Evans WC, Kling GW, Tuttle ML, Tanyileke G, and White LD. 1993. Gas buildup in Lake Nyos, Cameroon: The recharge process and its consequences. Appl. Geochem. 8: 207-221.

Freeth SJ. 1988. Constrains on the volume of carbon dioxide released during the 1986 Lake Nyos disaster. Trans. Am. Geophy. Un. 69: 1466.

Funicello R, Giordano G, and de Rita D. 2003. The Albano maar lake (Colli Albani volcano, Italy): recent volcanic activity and evidence of pre-Roman Age catastrophic lahar events. J. Volcanol. Geotherm. Res., 123: 43-61. doi:10.1016/S0377
$-0273(03) 00027-1$

Halbwachs M, Tietze K, Lorke A, and Mudaheranwa C. 2002. Investigations in Lake Kivu after the Nyiragongo Eruption of January 2002. Specific study of the impact of the subwater lava inflow on the lake stability. Report to Solidarités, Aide humanitaire d'urgence, Paris

Halbwachs M, Sabroux JC, Grangeon J, Kayser G, Tochon-Danguy JC, Felix A, Béard JC, Villevieille A, Vitter G, Richon P, Wüest A, and Hell J. 2004. Degassing the "killer lakes" Nyos and Monoun, Cameroon. Eos. 85(30): 281-288.

Hirslund F. (2012). Dynamic formation and flattening of chemoclines and the influence of the underlying mechanisms on the prevention of limnic eruption in Lake Kivu (Central Africa): submitted.

Huppert HE, and Turner JS. 1981. Double-diffusive convection. J. Fluid Mech. 106: 299-329.

Kling GW, MacIntyre S, Steenfelt J, and Hirslund F. 2006. Lake Kivu gas extraction - Report on lake stability. Report to the World Bank: $101 \mathrm{pp}$.

Lahmeyer International (co), and OSAE (co). 1998. Levée bathymétrique complet du Lac Kivu. Rapport final pour le ministère de travaux publics, Kigali, Rwanda.

Lorke A, Tietze K, Halbwachs M, and Wüest A. 2004. Response of Lake Kivu stratification to lava inflow and climate warming. Limnol. Oceanogr. 49(3): 778-783.

Muvundja F, Pasche N, Bugenyi FWB, Isumbisho M, Müller B, Namugize JN, Rinta P, Schmid M, Stierli R, and Wüest A. 2009. Balancing nutrient inputs to Lake Kivu. J. Great Lakes Res. 35(3): 406-418. DOI:10.1016/j.jglr. 2009.06.002.

Newman FC. 1976. Temperature steps in Lake Kivu: A bottom heated saline lake. J. Phys. Oceanogr. 6: 157-163.

Osborn TR. 1980. Estimates of the local rate of vertical diffusion from dissipation measurements. J. Phys. Oceanogr. 10: 8389.

Padman L, and Dillon TM. 1987. Vertical fluxes through the Beaufort sea thermohaline staircase. J. Geophys. Res. 92: 799-806.

Pasche N. 2009. Nutrient cycling and methane production in Lake Kivu. Thesis, ETH, Switzerland.

Pasche N, Alunga G, Mills K, Muvundja F, Ryves DB, Schurter M, Wehrli B, and Schmid M. 2010. Abrupt onset of carbonate deposition in Lake Kivu during the 1960s: response to recent environmental change. J. Paleolimnol. 44: 931-946. doi:10.1017/s10933-010-9465-x

Pollack HN, and Huang S. 2000. Climate reconstruction for subsurface temperatures. Annu. Rev. Earth Plan. Sci. 28: 339365.

Schmid M, Busbridge M, and Wüest A. 2010. Double-diffusive convection in Lake Kivu. Limnol. Oceanogr. 55(1): 225238.

Schmid M, Halbwachs M, and Wehrli B. 2004. Report of the scientific expeditions to Lake Kivu in November 2003 and February 2004. Report to the United Nation's Office for the Coordination of Humanitarian Affairs.

Schmid M, Halbwachs M, and Wüest A. 2006. Lake Nyos degassing scenarios. G3 Research Letter 6: Q06019, doi:10.1029/2005GC001164

Schmid M, Halbwachs M, Wehrli B, and Wüest A. 2005. Weak mixing in Lake Kivu: New insights indicate increasing risk of uncontrolled gas eruption. G3 Research Letter 6: Q07009, 
doi:10.1029/2004GC000892.

Schmid M, Lorke A, Wüest A, Halbwachs M, Wehrli B, and Tanyileke G. 2003. Development and sensitivity analysis of a model for assessing stratification and safety of Lake Nyos during artificial degassing. Ocean Dynamics, 53: 288-310, doi:10.1007/s10236-003-0032-0.

Sigurdsson H, Devine JD, Tchova FM, Presser TS, Pringle MKW, and Evans WC. 1987. Origin of the lethal gas burst from Lake Monoun, Cameroon. J. Volcanol. Geotherm. Res. 31: $1-6$.

TECHNIP (co), BRGM (co), SEDES (co), and SOGREAH. 1986. Mise en valeur du gaz méthane du lac Kivu. Étude de faisabilité - Phase 1, Rapport final, vol 1-3. Communauté Économique des Pays des Grands Lacs, Kigali.

Tedesco D, Tassi F, Vaselli O, Poreda RJ, Darrah T, Cuoco E, and Yalire MM. 2010. Gas isotopic signatures (He, C, and Ar) in the Lake Kivu region (western branch of the East African rift system): Geodynamic and volcanological implications. J. Geophys. Res. 115, B01205, doi:10.1029/ 2008JB006227.
Tietze K. 1978. Geophysikalische Untersuchung des Kivusees und seiner ungewöhnlichen Methangaslagerstätte - Schichtung, Dynamik und Gasgehalt des Seewassers. PhD dissertation from Christian Albrechts Universität, Kiel, Germany.

Turner JS. 1973. Buoyancy Effects in Fluids. Department of Applied Mathematics and Theoretical Physics, University of Cambridge. Cambridge, The University Press.

Umutoni A, Mugisha A, Nzayisenga T, and Rwandekwe L. 2009a. Baseline survey at REC concession site prior to the settlement of the platform on the 10th of June 2009. Monitoring report. Ministry of Infrastructure, Kigali, Rwanda.

Umutoni A, Mugisha A, Nzayisenga T, and Rwandekwe L. $2009 \mathrm{~b}$. Sebeya tracking field work conducted on the 29th of June 2009. Monitoring report. Ministry of Infrastructure, Kigali, Rwanda.

Wüest A, Jarc L, and Schmid M. 2009. Modelling the reinjection of deep-water after methane extraction in Lake Kivu. EAWAG and BTC for the Governments of Rwanda and DR Congo. 